\title{
Jornadas del Comité de Nefropatía de la Sociedad Argentina de Diabetes Actualización de cirugía bariátrica en paciente con diabetes y enfermedad renal. Parte 1
}

\author{
Conference of the Nephropathy Committee \\ of the Argentine Society of Diabetes \\ Bariatric surgery update in a patient with diabetes and kidney disease. Part 1
}

\author{
Comité de Nefropatía Diabética de la Sociedad Argentina de Diabetes \\ Expertos: Alicia Elbert ${ }^{1}$, Susana Gutt ${ }^{2}$, Estrella Menéndez ${ }^{3}$ \\ Participantes (en orden alfabético): María Florencia Aranguren ${ }^{4}$, Bárbara Arinovich ${ }^{5}$, Teresa Bensusan ${ }^{6}$, \\ Guillermo De’'Marziani' ${ }^{7}$, Guillermo Dieuzeide ${ }^{8}$, Gabriela Medek ${ }^{9}$, Liliana Miriam Obregon ${ }^{10}$, \\ María José Pomares ${ }^{11}$, Jimena Soutelo ${ }^{12}$, Fabiana Vázquez ${ }^{13}$, Gloria Viñes ${ }^{14}$, Mariela Volta ${ }^{15}$ \\ Coordinadoras: Fabiana Dávila ${ }^{16}$, Yanina Castaño ${ }^{17}$
}

\section{RESUMEN}

La prevalencia de obesidad y diabetes mellitus se asocia al desarrollo de enfermedad renal crónica y estadios terminales de la misma. En individuos con obesidad, se produce un mecanismo de hiperfiltración, probablemente compensatorio para satisfacer la alta demanda metabólica asociada al aumento del peso corporal, con la presencia de proteinuria, en individuos sin enfermedad renal. La histopatología muestra una glomeruloesclerosis focal y segmentaria relacionada con la obesidad en un marco de glomerulomegalia. La cirugía metabólica es el medio más efectivo para obtener una pérdida de peso sustancial y persistente. Se ha demostrado la superioridad de la cirugía sobre el tratamiento médico no solo para lograr un mejor control glucémico, sino también para la reducción de los factores de riesgo cardiovascular. Los mecanismos parecen extenderse más allá de la magnitud de la pérdida de peso e incluyen mejoras tanto en los perfiles de incretinas como en la secreción y la sensibilidad a la insulina.

El Comité de Nefropatía de la Sociedad Argentina de Diabetes realizó esta revisión sobre los mecanismos involucrados en la obesidad como causa de enfermedad renal o empeoramiento de la misma por diabetes, y los mecanismos a través de los cuales la cirugía bariátrica beneficiaría a los pacientes con diabetes y enfermedad renal crónica en todos los estadios de la misma, así como los controles pre y posquirúrgicos en este tipo de cirugías.

Palabras clave: obesidad; diabetes; cirugía bariátrica; cirugía metabólica; enfermedad renal crónica; glomerulopatía focal y segmentaria.

Revista de la Sociedad Argentina de Diabetes 2021; Vol. 55 (52-69)

\section{ABSTRACT}

The prevalence of obesity and diabetes mellitus are associated with the development of chronic kidney disease and its terminal stages. In individuals affected by obesity, a probably compensatory hyperfiltration mechanism occurs to satisfy the high metabolic demand associated with increased body weight; it is also associated with the presence and development of proteinuria in individuals without kidney disease. Histopathology shows obesity-related focal and segmental glomerulosclerosis in a setting of glomerulomegaly. Metabolic surgery is the most effective means of obtaining substantial and lasting weight loss. The superiority of surgery over medical treatment has been demonstrated only to achieve better glycemic control, as well as a reduction in cardiovascular risk factors. The mechanisms appear to extend beyond the magnitude of weight loss and include improvements in incretin profiles, insulin secretion, and insulin sensitivity.

The Nephropathy Committee of the Argentine Diabetes Society carried out this review on mechanisms involved in obesity as a cause of kidney disease or worsening of kidney disease due to diabetes, the mechanisms by which bariatric surgery would benefit patients with diabetes and kidney disease chronic and its terminal stages, the pre and post-surgical controls that should be performed by patients undergoing this type of surgery.

Key words: obesity; diabetes; bariatric surgery; metabolic surgery; chronic kidney disease; focal and segmental glomerulopathy. 
1 Médica especialista en Nefrología, especializada en Diabetes, Directora del Centro de Enfermedades Renales e Hipertensión Arterial (CERHA S.A.), Ciudad Autónoma de Buenos Aires, Argentina

2 Médica especialista en Nutrición, Jefa de Sección Nutrición, Servicio de Clínica Médica, Hospital Italiano de Buenos Aires, Ciudad Autónoma de Buenos Aires, Argentina

3 Médica especialista en Nutrición, Servicio de Nutrición y Diabetes, Centro de Educación Médica e Investigaciones Clínicas "Norberto Quirno" (CEMIC), Ciudad Autónoma de Buenos Aires, Argentina

4 Médica especialista en Medicina Interna, especializada en Diabetes, Hospital de Clínicas José de San Martín, Ciudad Autónoma de Buenos Aires, Argentina

5 Médica especialista en Medicina Interna y Nutrición, Consultorios Privados Cabildo y Céspedes, Ciudad Autónoma de Buenos Aires, Argentina

6 Médica especialista en Medicina Interna, especializada en Diabetes, Centro Médico Cepem, Morón, Provincia de Buenos Aires, Argentina

7 Médico especialista en Medicina Interna, especialista en Nefrología y Magister en Diabetes, Centro de Enfermedades Renales e Hipertensión Arterial (CEREHA S.A.), Provincia de Buenos Aires, Argentina

8 Doctor en Medicina, Universidad de Buenos Aires (UBA), especialista en Endocrinología, Jefe del Servicio de Endocrinología y Diabetes, Hospital Nuestra Señora del Carmen, Chacabuco, Provincia de Buenos Aires, Argentina

9 Médica especialista en Medicina Interna, especializada en Diabetes, Medical Scientific Laison Novo Nordisk, Vicente López, Buenos Aires, Consultorio de Diabetes Sanatorio Finochietto, Ciudad Autónoma de Buenos Aires, Argentina

10 Médica especialista consultor en Endocrinología, Jefa de Sala del Área de Trasplante Renal Centro Único Coordinador de Ablación e Implante de la Provincia de Buenos Aires (CUCAIBA-CRAI Sur-HIGA), Hospital General San Martín de La Plata, Provincia de Buenos Aires, Argentina

11 Médica especialista en Nefrología y especializada en Diabetes, Hospital Penna, Consultorios del Centro de Enfermedades Renales e Hipertensión Arterial (CEREHA S.A.), Ciudad Autónoma de Buenos Aires, Argentina
12 Médica endocrinóloga, Universidad de Buenos Aires (UBA), especializada en Diabetes, Servicio de Endocrinología, Hospital Churruca Visca, Ciudad Autónoma de Buenos Aires, Argentina

13 Médica especialista en Nutrición, especializada en Diabetes, Servicio de Endocrinología, Hospital Británico, sede Vicente Lopéz, Provincia de Buenos Aires, Argentina

14 Médica especialista en Nutrición, especializada en Diabetes, Jefa del Servicio de Nutrición y Diabetes, Hospital Privado de Comunidad, Mar del Plata, Provincia de Buenos Aires, Argentina

15 Licenciada en Nutrición, Universidad de Buenos Aires (UBA), Ciudad Autónoma de Buenos Aires, Argentina

16 Médica especialista en Nutrición, Servicio de Diabetes, Hospital Universitario Austral, Pilar, Provincia de Buenos Aires, Argentina

17 Médica especialista en Nutrición, Magister en Diabetes, Coordinadora del Área de Diabetes del Centro de Diálisis CETRO (Centro de Estudios y Tratamiento Renal Olavarría), Provincia de Buenos Aires, Argentina

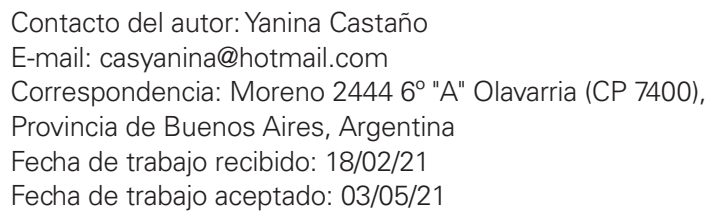

Conflictos de interés: la Dra. Susana Gutt declara haber recibido honorarios por consultoría, disertación y/o entrenamiento de disertantes de los laboratorios Novo Nordisk, Raffo y Bagó. La Dra. Fabiana Vázquez manifiesta haber recibido honorarios por consultoría, disertación y/o entrenamiento de disertantes de los laboratorios Novo Nordisk, Boehringer Ingelheim, AstraZeneca, Servier, Lilly y Merck. La Gloria Viñez declara haber recibido honorarios por consultoría, disertación y/o entrenamiento de disertantes de los laboratorios Servier, Boehringer Ingelheim, Novartis, Merck Sharp \& Dohme, Sanofi Aventis, Bayer y Novo Nordisk. El resto de los autores declara que no existe conflicto de interés.

\section{INTRODUCCIÓN}

La obesidad se ha convertido en una epidemia mundial y su creciente aumento tiene implicancias para el riesgo de desarrollar enfermedades como la diabetes mellitus (DM), enfermedad cardiovascular (ECV) y enfermedad renal crónica (ERC). Los cambios patológicos específicos en el riñón podrían producirse por la acumulación ectópica de lípidos, el desarrollo de hipertensión glomerular y el incremento de la permeabilidad glomerular, lo que genera hiperfiltración y consecuente daño en la barrera de filtración glomerular progresando finalmente al desarrollo de glomerulomegalia y glomeruloesclerosis focal y segmentaria. La incidencia de la glomerulopatía asociada a obesidad se ha incrementado en los últimos años.
También se ha postulado que la disbiosis, que consiste en los cambios en el perfil de la microbiota y la respuesta adversa del huésped, puede contribuir al desarrollo de distintas enfermedades. Los pacientes con ERC en todos los estadios presentan alteraciones cuantitativas y cualitativas en la microbiota intestinal.

En la actualidad la cirugía bariátrica (CB) es el tratamiento considerado más eficiente para la pérdida de peso y mantenimiento del mismo a largo plazo. Muchos estudios demostraron que la CB mejora la DM y sus complicaciones microvasculares, incluida la nefropatía, por lo cual hay que considerarla para el tratamiento de pacientes obesos con daño renal establecido. Los mecanismos parecen extenderse 
más allá de la magnitud de la pérdida de peso e incluyen mejoras en los perfiles de incretinas, en la secreción y la sensibilidad a la insulina y cambios en la microbiota.

Este tipo de cirugías se asocian a riesgos y complicaciones. La hiperoxaluria, la nefrolitiasis y el daño sobre el metabolismo mineral óseo son complicaciones a largo plazo de las CB malabsortivas.

Los pacientes con DM y ERC que se someterán a CB deben tener un control metabólico estricto y cercano acompañamiento del médico especialista en el período pre y posquirúrgico, por ejemplo, podrían presentarse hipoglucemias en pacientes que nunca antes las experimentaron debido al cambio rápido de la sensibilidad a la insulina poscirugía. La elección de la cirugía metabólica (CM), en pacientes con y sin ERC, implica además el adecuado tratamiento adecuado y de suplementación multivitamínica en las instancias pre y posquirúrgicas para lograr los resultados deseados.

Por lo mencionado anteriormente, destacamos que el objetivo de la Jornada Científica fue actualizar los conocimientos sobre epidemiología y fisiopatogenia de la cirugía bariátrica en el paciente con obesidad y DM, y su impacto en la función renal. Asimismo, abordamos las consecuencias metabólicas, el plan alimentario, las drogas antidiabéticas pre y pos-CB, así como también las repercusiones de la misma sobre las complicaciones renales a largo plazo.

\section{Epidemiología de la obesidad y DM (nacional y mundial) de enfermedad renal asociada a la obesidad. Perspectivas futuras}

La obesidad se ha convertido en una epidemia mundial y se prevé un aumento de su prevalencia en un $40 \%$ para la próxima década. Esta tendencia creciente tiene implicancias para el riesgo de desarrollar DM, ECV y ERC. Un elevado índice de masa corporal (IMC) es uno de los principales factores de riesgo para desarrollar ERC?

Según la Organización Mundial de la Salud (OMS), entre 1975 y 2016 la prevalencia mundial de obesidad se ha casi triplicado. En 2016, el $39 \%$ de los adultos $(39 \%$ hombres y $40 \%$ mujeres) tenía sobrepeso. A nivel mundial, el sobrepeso y la obesidad se vinculan a un mayor número de muertes que la insuficiencia ponderal ${ }^{2}$.

En Argentina, según la Cuarta Encuesta Nacional de Factores de Riesgo (4 ENFR 2018), la obesidad en adultos también aumentó de un
20,8 a un $25,4 \%$ en tan solo cinco años. El hecho de que el indicador de sobrepeso se haya mantenido estable solo expresa que un número significativo de personas que tenía sobrepeso pasó a la categoría de obesidad, y que una proporción de quienes tenían peso normal pasó a la categoría de sobrepeso ${ }^{3}$. Esto se evidencia con el incremento en la prevalencia de exceso de peso, expresado como la suma de sobrepeso y obesidad $^{3}$.

La prevalencia mundial de DM2 se ha incrementado en los últimos 30 años y se prevé que continúe en aumento a un ritmo alarmante. Si bien la principal fuerza impulsora para el incremento de la prevalencia de la DM2 es la obesidad, otros factores, entre ellos la genética y el medio ambiente, también contribuyen de manera importante a su desarrollo. La evidencia acumulada sugiere que la prevalencia marcadamente alta, tanto de la obesidad como de la DM2, contribuye al aumento de la incidencia de enfermedades crónicas, incluidas la ERC y la enfermedad renal crónica terminal (ERCT) $)^{4,5,6}$.

La prevalencia mundial de DM en adultos creció del 4,7\% en 1980 al 8,5\% en 2014, con mayor rapidez en los países de ingresos medianos y bajos ${ }^{6}$. Según proyecciones de la OMS, la DM será la séptima causa de mortalidad en $2030^{6}$.

En Argentina, según los resultados publicados en la $4^{\circ}$ ENFR, la prevalencia de DM aumentó de 9,8 a 12,7\% respecto de la edición anterior. Este incremento significativo era esperable dado que acompaña al crecimiento de la obesidad y la inactividad física, ambos factores de riesgo reconocidos de DM2.

Los países de bajos y medianos ingresos muestran evidencia de que la transición de peso normal a sobrepeso y a obesidad es similar a la que tuvieron los países desarrollados décadas atrás ${ }^{7}$. Esta prevalencia creciente de la obesidad tiene implicancias tanto para las enfermedades cardiovasculares como para la ERC. El elevado IMC es uno de los principales factores de riesgo para desarrollar ERC y ERCT ${ }^{8}$.

Tanto la obesidad como la ERC asociada son en gran medida prevenibles. Es fundamental educar y concientizar al equipo de salud y a la población sobre la importancia de un estilo de vida saludable para prevenir la obesidad y disminuir el riesgo de desarrollar otras enfermedades crónicas como DM2 y ERC. 


\section{BIBLIOGRAFÍA}

1. Kovesky CP, Furth SL, Zoccoli C. Obesity and kidney disease: hidden consequences of the epidemic. Canadian Journal of Kidney Health and Disease 2017; (4):1-10.

2. Organización Mundial de la Salud. 16 de febrero de 2018. Obesidad y sobrepeso. Disponible en: https://www.who.int/es/newsroom/fact-sheets/detail/obesity-and-overweight.

3. Cuarta Encuesta Nacional de Factores de Riesgo. Dirección Nacional de la Promoción de la Salud y control de Enfermedades Crónicas noTransmisibles. Principales resultados. 2018. Disponible en: https://bancos.salud.gob.ar/sites/default/files/202001/4ta-encuesta-nacional-factores-riesgo_2019_principalesresultados.pdf.

4. Foster MC, Hwang SJ, Larson MG, et al. Overweight, obesity, and the development of stage 3 CKD: the Framingham Heart
Study. Am J Kidney Dis 2008 Jul; 52(1):39-48.

5. Wang $Y$, Chen $X$, Song $Y$, et al. Association between obesity and kidney disease: a systematic review and meta-analysis. Kidney Int 2008 Jan; 73(1):19-33.

6. Mathers CD, Loncar D. Projections of global mortality and burden of disease from 2002 to 2030.PLoS Med 2006; 3(11):e442.

7. Subramanian SV, Perkins JM, Özaltin E, et al. Weight of nations: a socioeconomic analysis of women in low- to middleincome countries. Am J Clin Nutr 2011; 93(2):413-421.

8. Tsujimoto $\mathrm{T}$, Sairenchi $\mathrm{T}$, Iso $\mathrm{H}$, et al. The dose-response relationship between body mass index and the risk of incident stage $\geq 3$ chronic kidney disease in a general Japanese population: the Ibaraki prefectural health study (IPHS). J Epidemiol 2014; 24(6):444-451.

\section{La obesidad como causa de enfermedad renal. ¿Qué alteraciones produce? Mecanismos hemodinámicos y hormonales}

La obesidad es un importante factor de riesgo para el desarrollo de enfermedad renal ya que aumenta el riesgo de DM e hipertensión arterial (HTA), con impacto directo en la aparición de proteinuria, albuminuria y desarrollo de ERC y ERCT. En individuos con obesidad se produce un mecanismo de hiperfiltración, probablemente compensatorio, para satisfacer la alta demanda metabólica asociada al aumento de peso corporal. El aumento de la presión intraglomerular puede generar una lesión renal estructural e incrementar el riesgo de desarrollar ERC a largo plazo ${ }^{1,2,3}$.

\section{Mecanismos de acción subyacentes a los efectos renales de la obesidad}

La DM y la HTA, frecuentemente asociadas a obesidad, pueden producir efectos renales deletéreos. La actividad endocrina del tejido adiposo, mediante la producción de adiponectina, leptina y resistina (Figura 1), impacta directamente en los riñones a través de inflamación, estrés oxidativo, metabolismo lipídico anormal, activación del sistema renina-angiotensina-aldosterona (SRAA), incremento de la producción de insulina y mayor resistencia insulínica.

Los cambios patológicos específicos en el riñón podrían darse por la acumulación ectópica de lípidos, aumento de los depósitos grasos en el seno renal, desarrollo de hipertensión glomerular e incremento de la permeabilidad glomerular, lo que genera hiperfiltración y consecuente daño en la barrera de filtración glomerular, progresando finalmente al desarrollo de glomerulomegalia y glomeruloesclerosis focal y segmentaria. La incidencia de la glomerulopatía asociada a obesidad se ha incrementado hasta 10 veces en el período comprendido entre los años 1986 y 2000 '.

La obesidad se asocia también con factores de riesgo que contribuyen a una elevada incidencia y prevalencia de nefrolitiasis, como un menor $\mathrm{pH}$ urinario, aumento de oxalato urinario, y mayor excreción urinaria de ácido úrico, sodio y fósforo. Las dietas ricas en proteínas y sodio pueden contribuir a la acidificación de la orina y a la disminución del citrato urinario ${ }^{4}$.

Asimismo, la insulinorresistencia, la hiperinsulinemia crónica, el incremento en la producción de factor de crecimiento similar a la insulina tipo $1 \mathrm{y}$ fenómenos humorales secundarios pueden ejercer efectos estimulantes en el crecimiento de varios tipos celulares tumorales. Además, funciones endocrinas del tejido adiposo sobre la inmunidad y la generación de un estado proinflamatorio podrían explicar efectos complejos en el desarrollo de algunos tipos de cáncer.

\section{Obesidad en estadios tempranos de ERC}

La obesidad puede causar o agravar la ERC. Aspectos genéticos (mono o poligenéticos) o epigenéticos contribuyen al desarrollo de obesidad, aunque los mecanismos son poco claros. Los efectos metabólicos de diferentes adipocitoquinas (leptina, resistina, visfatin) y una down-regulation de la adiponectina contribuirían a cambios hemodinámicos y lesiones renales estructurales vía insulinorresistencia, hiperinsulinemia, activación del SRAA, estrés oxidativo y microinflamación ${ }^{5}$.

Estudios derivados de autopsias y biopsias 
renales detectaron que en la obesidad asociada a nefropatía (OAN) hay un aumento en tamaño y peso de nefronas. El incremento en el número de capilares glomerulares sugiere formación de novo de microvasos.

La aparición de albuminuria se asocia a glomeruloesclerosis focal y segmentaria (GEFS), y se acompaña por progresiva fibrosis túbulo-intersticial acorde con la pérdida de la función renal. Condiciones que reducen la masa nefronal, como bajo peso al nacer, anomalías congénitas de los riñones o de la vía urinaria y nefrectomía, contribuyen al progreso de la ERC en individuos obesos, mientras que una significativa reducción de peso en pacientes obesos disminuye la proteinuria ${ }^{4}$.

\section{Obesidad en estadios avanzados de ERC y diálisis: "una paradoja"}

En estadios avanzados de ERC se observó que individuos con IMC $\geq 40$ no tienen mayor riesgo de muerte, especialmente si la ganancia de peso es en peso magro, masa muscular ${ }^{4}$.

\section{Rol de la obesidad en trasplante renal}

En algunos estudios se detectó que la obesidad puede aumentar el riesgo de muerte, de rechazo agudo y pérdida del injerto. Por lo tanto, se recomienda la pérdida de peso en pacientes con trasplante renal ${ }^{4}$. Existe evidencia que la $\mathrm{CB}$, en pacientes trasplantados renales, favorece la disminución de la proteinuria y mejora el filtrado glomerular ${ }^{6}$.

\section{Rol de los riñones en la obesidad, síndrome metabólico y DM2}

La combinación de efectos sistémicos y locales directos del depósito ectópico de lípidos a nivel renal debe considerarse como una nueva entidad clínica denominada "enfermedad por riñón graso" (ERG). Este depósito ectópico de lípidos puede ser para-renal (por encima de la fascia renal), peri-renal (entre la fascia y la cápsula renal), ubicarse en el hilio renal y comprimir los vasos y la inervación simpática o puede comprometer el parénquima. Existen mecanismos por los cuales la ERG contribuye a la hiperglucemia, HTA y aparición-progresión de ERC:

- Mecanismo por el cual el "riñón graso" desarrolla hiperglucemia

Tanto en síndrome metabólico (SM) como en DM2, el depósito y la acumulación de ácidos grasos libres ( $A G L$ ) y triglicéridos (TG) en la cortical renal generan hiperglucemia directamente a través del aumento de la gluconeogénesis renal (GR) y la resistencia a la insulina (RI). Normalmente, la GR en ayunas representa el $25 \%$ de la gluconeogénesis total y en el estado posprandial más del $50 \%$. La fuente renal para la gluconeogénesis son el lactato y la glutamina. En la obesidad, la GR posprandial es casi igual a la hepática y en la obesidad asociada a DM2, el depósito aumentado de TG y la mayor actividad de la enzima fosfoenolpiruvatoquinasa, incrementan aún más la GR. La hiperglucemia crónica aumenta la síntesis de lípidos, la acumulación de TG a nivel renal e interfiere con el ingreso al ciclo de Krebs de los AGL para su catabolismo. La inhibición de la utilización de glucosa por los AGL es característica de la RI. Así podemos afirmar que los dos factores que contribuyen a la hiperglucemia en el "riñón graso" son el aumento de la GR y la interferencia de los AGL en la utilización renal normal de la glucosa?.

- Mecanismo por el cual el "riñón graso" desarrolla hipertensión

La obesidad visceral puede producir aumento de la presión intraabdominal y retroperitoneal, la cual es transmitida directamente al parénquima renal. El efecto mecánico del acúmulo de grasa contribuye a la hipertensión al comprimir los vasos renales y disminuir la irrigación, estimulándose el SRAA, cuyo efecto principal es aumentar la reabsorción tubular de sodio, expandir el volumen y la formación de angiotensina II (factores que contribuyen a la hiperfiltración e HTA). Adicionalmente, los adipocitos son capaces de secretar todos los componentes del SRAA.

Un estudio demostró que todos los componentes del SRAA estaban elevados en la obesidad, y disminuyeron significativamente luego de la pérdida de peso: angiotensinógeno $27 \%$, renina $43 \%$, aldosterona $31 \%$ y angiotensina $20 \%$. Esto se acompañó de una reducción de $7 \mathrm{mmHg}$ en la tensión arterial sistólica ${ }^{8}$.

Asimismo, en la obesidad, la secreción de aldosterona no ocurre solo por la acción de la angiotensina en la capa glomerulosa, sino también por una vía aún no bien conocida, relacionada probablemente con la secreción en adipocitos viscerales?.

- Mecanismo por el cual los "riñones grasos" conducen a $E R C$

Estudios epidemiológicos hallaron una significativa correlación entre obesidad y aparición/progresión de albuminuria y ERC. La presión mecánica 
causada por el depósito ectópico de grasa produce injuria tubular renal, y el depósito de grasa intrarrenal cortical favorece la ERC mediante lipotoxicidad, inflamación, apoptosis, injuria podocitaria y fibrosis intersticial. La lipotoxicidad también ocurre en las células tubulares y causa disfunción mitocondrial, aumento de especies reactivas de oxígeno (ROS, por sus siglas en inglés), liberación de citoquinas e inicio de la fibrogénesis renal. Cuando los AG ingresan a la cortical renal son depositados como gotas intracelulares; esto ha sido considerado en la patogenia de la enfermedad renal por DM, nefroesclerosis hipertensiva y otras entidades.

La acumulación renal de TG puede ocurrir sin hiperlipidemia, vía up-regulation de las proteínas que se unen a los elementos regulatorios de esteroles (SREBP-1c). La hiperglucemia aumenta la síntesis y la acumulación renal de TG. El exceso de TG aumenta la formación de diacilglicerol y ceramidas con liberación de citoquinas que contribuye a la fibrosis intersticial, IR y pérdida de la función renal?.

- Mecanismo del riñón graso en la hiperleptinemia

La activación del SRAA en la obesidad contribuye a la estimulación del sistema nervioso simpático y a la hiperleptinemia. En los riñones hay receptores para leptina, la cual puede aumentar directamente la reabsorción tubular de sodio y la expansión del volumen y, consecuentemente, la presión arterial. La hiperleptinemia estimula la proliferación celular endotelial glomerular al provocar glomeruloesclerosis focal con albuminuria generando fibrosis intersticial vía expresión del TGF beta (factor de crecimiento tumoral beta) y colágeno tipo IV, y modulación del óxido nítrico y del tono vascular?.

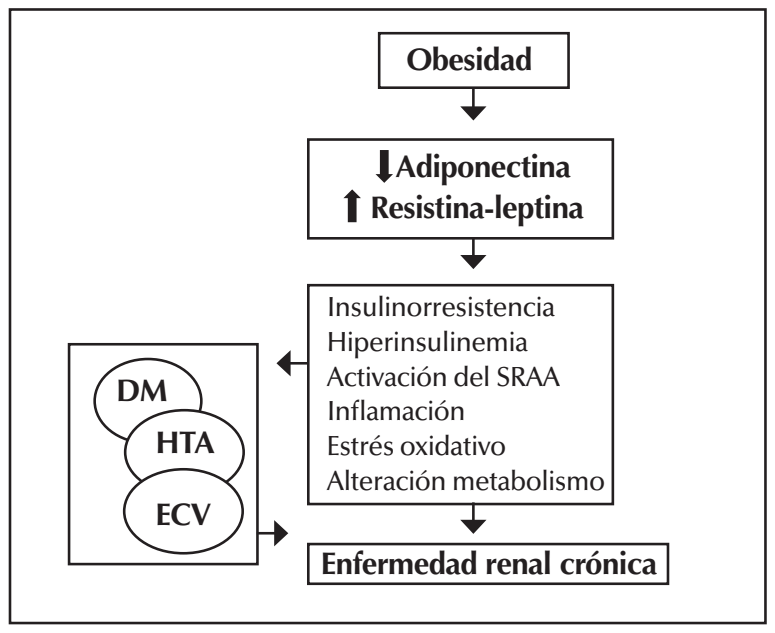

Adaptación de: Kovesdy et al. ${ }^{1}$.

DM: diabetes mellitus; HTA: hipertensión arterial; ECV: enfermedad cardiovascular; SRAA: sistema renina-angiotensina-aldosterona.

Figura 1: Mecanismos responsables mediante los cuales la obesidad causa el daño renal.

\section{BIBLIOGRAFÍA}

1. Kovesdy CP, Furth S, Zoccali C. Obesidad y enfermedad renal: consecuencias ocultas de la epidemia. Nefrología 2017; 37(4):360-369.

2. Resenstock JL, Pommier M, Stoffels G, et al. Prevalence of proteinuria and albuminuria in an obese population and associated risk factors. Front Med (Lausanne) 2018 Apr 30; 5:122. DOI: 10.3389/fmed.2018.00122. eCollection 2018.

3. Shulman A, Peltonen M, Sjöström CD, et al. Incidence of endstage renal desease following bariatric surgery in the Swedich obese subjects study. Int J Obes 2018; 42(5): 964-973. DOI: 10.1038/s41366-018-0045.

4. PommerW. Preventive nephrology: the role of obesity in different stages of chronic kidney disease. Kidney Dis 2018; 4:199-204.
5. Khoury LE, Chouillard E, Chahine E, et al. Metabolic surgery and diabesity: a sistematic review. Obes Surg 2018; 28(7):2069-2077.

6. Bilha SC, Nistor I, Nedelcu A, et al. The effects of bariatric surgeryon renal outcomes: a sistematic review and meta-analysis. Obes Surg 2018; 28(12):3815-3833.

7. Mende CW, Einhorn D. Fatty kidney disease: a new renal and endocrine clinical entity? Describing the role of the kidney in obesity, metabolic syndrome and type 2 diabetes. Review article. Endo Pract 2019; 25(8):854-858.

8. Engeli S, Böhnke J, Gorzelniak K, et al. Weight loss and the renin-angiotensin-aldosterone system. Hypertension 2005; 45 (3):356-62. 


\section{Microbiota intestinal, obesidad, SM, DM2 y ERC}

La microbiota intestinal es la comunidad de microorganismos vivos residentes en el intestino y sus alteraciones podrían contribuir en parte con el desarrollo de algunas patologías como la obesidad y la DM2. La población en colon asciende a $1,0^{12}-1,0^{14}$, siendo esta cifra mayor que el de las células humanas'. Cumple funciones sobre la nutrición ya que interviene en el procesamiento de componentes indigeribles de la dieta como polisacáridos vegetales, la síntesis de aminoácidos esenciales y vitaminas, la homeostasis metabólica y la regulación inmunológica?.

La microbiota intestinal es diferente para cada individuo y existe un balance saludable entre huésped-microorganismos que posibilita que las funciones anteriormente mencionadas se desarrollen de manera óptima².

La microbiota intestinal incluye especies nativas que colonizan permanentemente el tracto gastrointestinal (TGI) y microorganismos que lo colonizan transitoriamente.

Las alteraciones de la microbiota intestinal y la respuesta adversa del huésped se denominan disbiosis y se asocia con diferentes patologías como obesidad, SM y DM2.

Las bacterias son trillones de microorganismos que constituyen $\sim 50 \%$ de la masa fecal. Los filos microbianos intestinales dominantes son firmicutes (GRAM+), bacteroidetes (GRAM-), actinobacteria, proteobacteria, fusobacteria y verrucomicrobia. Los filos firmicutes y bacteroidetes representan el $90 \%$ de la microbiota intestinal. El filo firmicutes está compuesto por más de 200 géneros diferentes como Lactobacillus, Clostridium, Enterococcus y Ruminicoccus. El género Clostridium representa el 95\% del filo firmicutes. El filo bacteroidetes se constituye de géneros predominantes como Bacteroides y Prevotella. El filo actinobacteria es proporcionalmente menos abundante, representado principalmente por el género Bifidobacterium².

El ser humano intraútero carece de microbiota y el TGI se coloniza inmediatamente al nacer. A lo largo de la vida, la composición microbiana dependerá de la genética, edad, tipos de fuentes nutricionales, enfermedades, uso de antibióticos, etc. ${ }^{1,2,3}$.

En este texto nos referiremos fundamentalmente a la relación entre la microbiota y la homeostasis metabólica.

\section{Efectos metabólicos de la microbiota intestinal}

La microbiota intestinal cumple algunos de los siguientes efectos metabólicos:

- Efectos por su actividad enzimática fermentativa sobre polisacáridos complejos no digeribles con la consecuente generación de monosacáridos (MS) y ácidos grasos de cadena corta (AGCC).

- Efectos por sus endotoxinas: endotoxemia metabólica.

- Efectos por su actividad enzimática sobre las proteínas.

\section{Microbiota en condiciones fisiológicas}

1. Bacterias y monosacáridos en condiciones fisiológicas normales

Los MS provenientes de la fermentación bacteriana activan la ChREBP (proteína de unión a elemento de respuesta a carbohidratos), el mayor factor de transcripción activado por la glucosa que se encuentra altamente expresado en hígado, células $\beta$ pancreáticas, tejido adiposo blanco y pardo y músculo, que tiene capacidad de regular el metabolismo de la glucosa y los lípidos a través de la regulación de la expresión genética de las vías de la glucólisis, gluconeogénesis y lipogénesis ${ }^{4}$.

\section{Bacterias y AGCC en condiciones fisiológicas normales}

a) Los AGCC, fundamentalmente propiónico, butírico y acético (proporción habitual 1-1-3), son efectores de las actividades de la microbiota relacionadas con:

- El metabolismo de la glucosa y de los lípidos.

- El apetito y la homeostasis de la energía.

- Las actividades anticancerígenas, antioxidantes e inmunomoduladoras.

A nivel del hígado, tejido adiposo blanco y pardo y músculo esquelético regulan la expresión genética de las vías de la glucólisis, gluconeogénesis y lipogénesis ${ }^{5}$.

El propionato y el acetato son producidos principalmente por bacteroidetes, mientras que el butirato es dominantemente producido por firmicutes. Sin embargo cada AGCC no es de síntesis exclusiva de cada filo bacteriano ${ }^{3,6}$.

Si bien la luz intestinal es el principal sitio de producción de los AGCC, el gradiente de concentración cae desde la luz hacia la periferia con una captación preferencial de butirato por el epitelio intestinal, propionato por el hígado y acetato por los tejidos periféricos?. 
En el hígado, el propionato puede activar la gluconeogénesis e inhibir la lipogénesis, mientras que el acetato es el principal AGCC sustrato para la lipogénesis hepática y promueve la lipogénesis en tejido adiposo blanco. El butirato estimula la lipólisis en tejido adiposo y la $\beta$ oxidación de los $A G L^{3}$.

$\mathrm{El}$ acetato parece ser "predominantemente" obesogénico, mientras butirato y propionato "predominantemente" antiobesogénicos", pero ninguno de los tres cumple esta función de manera pura ya que se pueden comportar en uno u otro sentido.

El butirato es la principal fuente de energía de los colonocitos, incrementa la actividad mitocondrial, previene la endotoxemia metabólica, mejora la sensibilidad insulínica, tiene actividad antiinflamatoria y anticancerígena, protege la integridad de la barrera intestinal y favorece la hipofagia.

El propionato inhibe la síntesis de colesterol antagonizando el efecto del acetato e inhibe la expresión de resistina en los adipocitos. El propionato y el acetato regulan el peso al actuar sobre hormonas anorexígenas intestinales. El acetato es potencialmente obesogénico por actuar como sustrato para la lipogénesis hepática y adipocitaria ${ }^{6}$.

El acetato ha sido vinculado con la supresión de la lipólisis adipocitaria periférica, por lo tanto, reduce el flujo de AGL hacia el hígado mitigando el deterioro inducido por el hígado graso sobre la homeostasis de la glucosa. Por otro lado, su elevación en plasma está inversamente relacionada con los niveles de insulina plasmática. Un mecanismo para explicar este efecto involucra una mejor respuesta de la insulina en las células $\beta$ pancreáticas mediada por los GPR-43 receptores acoplados a la proteína G-43 lo que induce un mejor control glucémico?.

Como se menciona en el párrafo anterior, parte de los efectos metabólicos de los AGCC se realiza a través de su actividad sobre los GPR-41 también llamado FFAR-3 (receptor de ácidos grasos libres-2) y GPR-43 también denominado FFAR-2. Ambos GPRs están presentes además en adipocitos, células epiteliales y enteroendocrinas. Su estímulo produce aumento de la síntesis de PYY y GLP-1 (péptido YY y péptido símil al glucagon-1: ambos de efecto anorexígeno) por lo que modulan el eje intestino-hipotálamo, favorecen el aumento de la motilidad intestinal y disminuyen la cosecha de energía de los alimentos. El estímulo del GPR-43 reduce la liberación de AGL a la circulación al mejorar la sensibilidad a la insulina. El GPR-41 aumenta la expresión de leptina en adipocitos ${ }^{6}$.
Por otra parte, algunos componentes microbianos por sí mismos, como la proteína chaperona $\mathrm{ClpB}$, mimetizan al POMC (propiomelanocortina) precursor de la $\alpha-\mathrm{MSH}$ (melanocortina) de efecto anorexígeno, lo cual se suma al efecto de los AGCC sobre el control del apetito ${ }^{5}$.

En las Tablas 1, 2 y 3 se describen algunos de los mecanismos por los cuales actúan los AGCC y las vías efectoras hasta ahora conocidas.

b) Los AGCC en condiciones fisiológicas normales aumentarían la expresión intestinal del FIAF (fasting-induced adipose factor o factor adiposo inducido por el ayuno), también Ilamado ANGPTL-4 (angiopoietin-like 4).

La microbiota regula la expresión del FIAF intestinal, que es un inhibidor circulante de la lipoproteinlipasa (LPL) que favorece la captura de los ácidos grasos y el aumento del tejido adiposo. Algunos trabajos demostraron que AGCC como el butirato pueden aumentar la expresión del FIAF intestinal de manera PPAR- $\gamma$ independiente. Sin embargo, la coestimulación con ligandos del PPAR- $\gamma$ conjuntamente con AGCC produce un aumento de los niveles del FIAF. Estudios sobre líneas celulares de adenocarcinoma de colon señalaron que concentraciones fisiológicas de AGCC indujeron la expresión del FIAF por activación del PPAR- $\gamma$. Sin embargo, el mecanismo definitivo por el cual los AGCC modifican la expresión del FIAF queda aún por dilucidarse $e^{8,9,10}$.

c) Los AGCC y mucosa intestinal: función de barrera y angiogénesis en condiciones fisiológicas normales.

La microbiota promueve la función de barrera intestinal a través de la acción de los AGCC. El butirato favorece las uniones intercelulares de la mucosa intestinal por estimular la expresión genética de las proteínas de unión estrecha zonulina y ocludina que mantienen la adecuada función de barrera-permeabilidad intestinal. También inhibe la angiogénesis de la mucosa intestinal y favorece la apoptosis de células neoplásicas contribuyendo en la prevención del cáncer colorrectal (CCR) $)^{6,11}$.

\section{Bacterias y termogénesis: sistema endocanna-} binoide (SEC) y empardamiento en condiciones fisiológicas normales

EI SEC juega un rol clave en la homeostasis de la energía dado que regula el apetito, la distribución y expendio de energía, la expansión del tejido adiposo, la homeostasis de la glucosa y la regulación de la inflamación. En estudios con animales, la microbiota intestinal y el SEC se modulan mutuamente. Por 
ejemplo, la presencia de Lactobacillus acidophilus (filo firmicutes) ha mostrado que induce la expresión de receptores cannabinoides en las células intestinales, generando cambios en la permeabilidad. Desafortunadamente, los datos se basan predominantemente en estudios animales. En humanos, la relación directa entre los cambios en la microbiota intestinal y el tono del SEC todavía debe demostrarse concluyentemente ${ }^{5}$.
Por otra parte, estudios que revisaron el vínculo entre la exposición al frío y la microbiota resaltan que una cepa bacteriana específica, la Akkermansia muciniphyla (filo verrucomicrobia) cuya presencia o ausencia parece modular la eficiencia energética en función del estado nutricional del huésped o de la temperatura ambiente, actuaría como un sensor de energía 5 .

\begin{tabular}{|c|c|c|c|}
\hline AGCC & Sitio de acción & $\begin{array}{l}\text { Receptores, efectores } \\
\text { y vías conocidas }\end{array}$ & Efectos metabólicos \\
\hline Acetato & Hígado & PPAR $\alpha$ a través de vía AMPK & $\begin{array}{l}\text { Disminución del contenido lipídico (recibe menos AGL por } \\
\text { actividad antilipolítica periférica) } \\
\text { Aumento de la termogénesis relacionado a expresión genética } \\
\text { Aumento de oxidación grasa relacionado a expresión genética }\end{array}$ \\
\hline $\begin{array}{l}\text { Principalmente sintetizados } \\
\text { por bacteroidetes }\end{array}$ & & No descripto & $\begin{array}{l}\text { Aumento de función mitocondrial } \\
\text { Disminución de inflamación } \\
\text { Principal AGCC sustrato para lipogénesis } \\
\text { Disminución transporte de glucosa }\end{array}$ \\
\hline \multirow[t]{3}{*}{$\begin{array}{l}\text { Mayor captación por tejidos } \\
\text { periféricos }\end{array}$} & \multirow[t]{3}{*}{ Tejido adiposo blanco } & $\begin{array}{l}\text { GPR-43 (o FFAR2) } \\
\text { PPAR- } \gamma 2\end{array}$ & $\begin{array}{l}\text { Actividad antilipolítica (por lo que mejora la sensibilidad a la } \\
\text { insulina) } \\
\text { Promueve lipogénesis } \\
\text { Estimula diferenciación adipocito }\end{array}$ \\
\hline & & GPR-43 & $\begin{array}{l}\text { Actividad antilipolítica } \\
\text { Disminuye AGL plasma }\end{array}$ \\
\hline & & MCT-1 & Pardeamiento \\
\hline $\begin{array}{l}\text { Actividad predominantemente } \\
\text { obesogénica }\end{array}$ & Hipotálamo & AMPK hipotalámica & $\begin{array}{l}\text { Reduce ingesta alimentaria modulando la actividad de neuro- } \\
\text { nas en ARC }\end{array}$ \\
\hline
\end{tabular}

Modificado de: Cani et al. 5 .

PPAR: receptor del proliferador activado de peroxisoma; AMPK: adenosina monofosfato kinasa; MCT-1: transportador de monocarboxilato-1; AGL: ácidos grasos libres; ARC: núcleo arcuato; AGCC: ácidos grasos de cadena corta; GPR-43: receptores acoplados a la proteína.

Tabla 1: AGCC y regulación genética del metabolismo.

\begin{tabular}{|c|c|c|c|}
\hline AGCC & Sitio de acción & $\begin{array}{l}\text { Receptores, efectores } \\
\text { y vías conocidas }\end{array}$ & Efectos metabólicos \\
\hline \multirow[t]{2}{*}{ Propionato } & Intestino & GPR-41 AMPC & $\begin{array}{l}\text { Promueve gluconeogénesis intestinal } \\
\text { Controla homeostasis de la glucosa }\end{array}$ \\
\hline & Colon & GRP-41 y GPR-43 & $\begin{array}{l}\text { Estimula liberación de GLP-1 y PYY } \\
\text { Reduce ingesta alimentos }\end{array}$ \\
\hline $\begin{array}{l}\text { Principalmente sintetizados } \\
\text { por bacteroidetes }\end{array}$ & $\begin{array}{l}\text { Sitio no especificado } \\
\text { (¿intestino?) }\end{array}$ & GPR-43 & $\begin{array}{l}\text { Estimula la producción de hormonas intestinales } \\
\text { Reduce ingesta de alimentos } \\
\text { Protege contra la obesidad inducida por dieta }\end{array}$ \\
\hline \multirow[t]{2}{*}{$\begin{array}{l}\text { Principalmente captado por } \\
\text { hígado }\end{array}$} & Tejido adiposo blanco & GRP-43 PPAR- $\gamma 2$ & $\begin{array}{l}\text { Actividad antilipolítica (in vitro) } \\
\text { Promueve acumulación grasa (in vitro) } \\
\text { Estimula diferenciación adipocito (in vitro) }\end{array}$ \\
\hline & & GRP-43 & $\begin{array}{l}\text { Actividad antilipolítica (in vitro) } \\
\text { Disminuye AGL plasmáticos (in vivo) lo que aumenta la } \\
\text { sensibilidad a la insulina }\end{array}$ \\
\hline $\begin{array}{l}\text { Actividad predominantemente } \\
\text { antiobesogénica }\end{array}$ & Hígado & $\begin{array}{l}\text { Acetil-CoA sintetasa } \\
\text { Actúa sobre transcripción genética } \\
\text { de pasos limitantes de lipogénesis } \\
\text { de novo (acetil CoA caboxilasa, } \\
\text { ácido graso sintetasa, etc.) }\end{array}$ & $\begin{array}{l}\text { Inhibe la síntesis de colesterol } \\
\text { Inhibe la lipogénsis } \\
\text { AGCC precursor para gluconeogénesis }\end{array}$ \\
\hline
\end{tabular}

Modificado de: Cani et al. ${ }^{5}$.

AGCC: ácidos grasos de cadena corta; AGL: ácidos grasos libres; GPR-41/ GPR-43: receptores acoplados a la proteína.

Tabla 2: AGCC y regulación genética del metabolismo. 


\begin{tabular}{|c|c|c|c|}
\hline AGCC & Sitio de acción & $\begin{array}{l}\text { Receptores, efectores } \\
\text { y vías conocidas }\end{array}$ & Efectos metabólicos \\
\hline Butirato & Intestino & GPR-41 AMPc & $\begin{array}{l}\text { Promueve gluconeogénesis intestinal } \\
\text { Controla homeostasis de la glucosa }\end{array}$ \\
\hline Sintetizado principalmente por firmicutes & $\begin{array}{l}\text { Sitio no especificado } \\
\text { (¿intestino?) }\end{array}$ & GRP-43 & $\begin{array}{l}\text { Estimula producción de hormonas intestinales GLP-1 } \\
\text { Reduce ingesta de alimentos } \\
\text { Protege contra obesidad inducida por dieta }\end{array}$ \\
\hline Mayor concentración en epitelio intestinal & $\begin{array}{l}\text { Tejido adiposo } \\
\text { blanco }\end{array}$ & $\begin{array}{l}\text { GRP-43 } \\
\text { Arß3ATGLp-HSL }\end{array}$ & $\begin{array}{l}\text { Estimula lipólisis } \\
\text { Reduce tamaño adipocitos } \\
\text { Aumenta la fosforilación oxidativa mitocondrial }\end{array}$ \\
\hline Actividad predominantemente antiobesogénica & $\begin{array}{l}\text { Tejido adiposo } \\
\text { pardo }\end{array}$ & $\begin{array}{l}\text { AMPK } \\
\text { PGC1 } \alpha \text { UPC-1 }\end{array}$ & $\begin{array}{l}\text { Estimula lipólisis } \\
\text { Estimula función mitocondrial } \\
\text { Aumenta termogénesis }\end{array}$ \\
\hline Previene endotoxemia metabóloca & Músculo esquelético & $\begin{array}{l}\text { AMPK vía PGC1 } \alpha \\
\text { PPAR5 }\end{array}$ & $\begin{array}{l}\text { Aumenta función mitocondrial } \\
\text { Aumenta oxidación de AG } \\
\text { Aumenta tasa de fibras }\end{array}$ \\
\hline $\begin{array}{l}\text { Favorece función de barrera epitelial intestinal } \\
\text { Actividad antiinflamatoria y anticancerígena }\end{array}$ & $\begin{array}{l}\text { Terminaciones } \\
\text { vagales intestinales }\end{array}$ & No descripto & Inhibe la actividad de neuronas orexígenas en ARC \\
\hline
\end{tabular}

Modificado de: Cani et al. 5 .

ARß 3: receptor $\beta$ adrenérgico 3; GPR-41/GPR43: receptores acoplados a la proteína; $p$-HSL: lipasa hormono sensible fosforilada; PGC-1 $\alpha$ : proteína coactivadora del receptor activado por el proliferador de peroxisomas 1 $\alpha$; UCP-1: proteína desacoplante-1; AGCC: ácidos grasos de cadena corta.

Tabla 3: AGCC y regulación genética del metabolismo.

\section{Microbiota, obesidad y DM2}

La disbiosis puede contribuir al desarrollo de distintas enfermedades. Estudios realizados tanto en ratones como en humanos demostraron que la microbiota intestinal difiere en su composición entre obesos y delgados. En un modelo de ratones ob/ob deficientes en leptina, Ley et al. encontraron un aumento de la relación firmicutes/bacteroidetes, los dos filos bacterianos intestinales dominantes. Los ratones obesos mostraron un aumento de firmicutes y disminución de bacteroidetes, comparados con los magros ${ }^{12}$. Cuando Ley et al. evaluaron lo mismo en humanos delgados vs obesos, encontraron diferencias similares ${ }^{13}$.

En el estado de obesidad existe un cambio pronunciado en la ecología microbiana asociada a la patología del huésped. La convivencia de bacteroidetes y firmicutes en el intestino implica una minimización de la competencia por los recursos a través de la cooperación o la especialización. Por lo tanto, el colon de sujetos obesos tiene propiedades que inclinan el equilibrio hacia el aumento de firmicutes: "microbiota obesa"13.

La misma alteración (aumento de firmicutes y disminución de bacteroidetes) está asociada y/o predice el desarrollo de resistencia insulínica/DM2 de tal forma que se la considera como un futuro potencial marcador clínico de $\mathrm{DM} 2^{14}$.

Múltiples estudios confirmaron que las alte- raciones de la microbiota de los sujetos obesos pueden relacionarse con una mayor capacidad para extraer o "cosechar" energía de los alimentos, comparados con sujetos delgados ${ }^{14}$.

Si comparamos lo expuesto anteriormente durante una condición fisiológica normal vs sujetos obesos-DM2, en este último grupo hay un aumento de la capacidad para cosechar la energía de los alimentos, lo cual puede explicarse por varios mecanismos relacionados con la disbiosis descripta.

En sujetos con obesidad-DM2 se ha encontrado:

- Incremento de MS circulantes y por lo tanto de la captura de los mismos a nivel hepático, lo cual activa la ChREBP al favorecer la lipogénesis, y alterar la glucólisis y gluconeogénesis ${ }^{1,15,16}$.

- Todas las funciones que los AGCC cumplen sobre el metabolismo de los $\mathrm{H}$ de $\mathrm{C}$ y los lípidos se ven alteradas, ya que al variar la microbiota varía la concentración de cada AGCC y sus funciones (el desequilibrio en la síntesis de butirato puede provocar disminución de la lipólisis, de la oxidación de los AGL y la termogénesis). En la disbiosis se observa una disminución de la expresión del FIAF, lo cual favorecerá la actividad de la LPL aumentando los AGL circulantes provenientes de los triglicéridos y su posterior captura con expansión del tejido adiposo 1,16,17. También se altera el eje intestino-hipotálamo y los niveles de péptidos anorexígenos ${ }^{5}$.

- La disbiosis aumenta la vascularización y el 
flujo sanguíneo dentro de la mucosa intestinal, facilitando la absorción de nutrientes ${ }^{1,18}$.

Todos los mecanismos conducen a un aumento de la cosecha de energía de los alimentos.

\section{Endotoxemia metabólica}

Las bacterias Gram (-) (70\% del total de bacterias en el intestino) tienen en su membrana externa un componente glicolipídico principal: un lipopolisacárido (LPS) con acción de endotoxina ${ }^{19}$.

La microbiota obesa y sus cambios en las concentraciones de AGCC, fundamentalmente del butirato, se relacionan con la reducción de la expresión de los genes para las proteínas de unión estrecha intestinal que se muestran menos abundantes y desorganizadas en el colon, favoreciendo el pasaje de endotoxinas a través de la barrera alterada. El ingreso de las endotoxinas de las bacterias exógenas puede ser por vía local o por una infección sistémica, y el de las endógenas a través del intestino luego de la lisis de la célula bacteriana por absorción paracelular o por transporte transcelular6,19.

La endotoxemia puede originar un cuadro de infección/sepsis o un cuadro metabólico denominado "endotoxemia metabólica".

Cani et al. describieron la "endotoxemia metabólica" como una condición del LPS plasmático crónicamente elevado en niveles 10 a 50 veces más bajos que durante las condiciones sépticas. La endotoxemia metabólica se observó en ratones genéticamente obesos (ob/ob) que consumían dieta normocalórica y se pudo inducir en ratones magros con una dieta obesogénica. Esto se relacionó con un aumento del depósito de grasa, activación de las vías inflamatorias y oxidativas, y un incremento de la resistencia insulínica ${ }^{20}$.

Estudios en humanos también mostraron una elevación del LPS circulante en individuos obesos vs delgados ${ }^{21}$.

El componente lipídico del LPS (lípido A) inicia una cascada de señalizaciones al unirse al receptor tipo Toll 4 (TLR4) presente en células inmunológicas, músculo esquelético, hígado y tejido adiposo, activando al factor de transcripción NFאB (factor nuclear $\kappa \mathrm{B}$ ) lo cual resulta en un aumento de la expresión de proteínas proinflamatorias (por ejemplo, PAI-1, TNF $\alpha$, IL6, IL-1) y ROS generando un estado inflamatorio de bajo grado, que también caracteriza a la obesidad, la DM2, la enfermedad cardiovascular y la aterosclerosis. Este estado in- flamatorio generado por la endotoxemia juega un rol importante en la regulación de la homeostasis de la glucosa y los lípidos ${ }^{19}$.

\section{Microbiota en la enfermedad renal}

Los pacientes con ERC y ERCT tienen alteraciones cuantitativas y cualitativas en la microbiota intestinal. Esta disbiosis puede producirse por la uremia per se o relacionarse con modificaciones de la dieta, como disminución de la ingesta de fibra y líquidos y situaciones de tratamiento (como el uso recurrente de antibióticos o hierro oral), acidosis metabólica, empeoramiento de la asimilación proteica y enlentecimiento del tránsito intestinal22,23.

Las alteraciones de la microbiota intestinal incluyen un aumento de bacterias aerobias y anaerobias en duodeno y yeyuno, y una disminución en todo el intestino delgado de lactobacillaceae y prevotellaceae. En colon hay un sobrecrecimiento de bacterias aerobias 100 veces mayor, con aumento de proteobacterias, enterobacterias, clostridium perfringens y disminución de lactobacilos y bifidobacterias, con alto riesgo de diarreas por clostridium difficile $e^{22,23}$.

Esta microbiota intestinal disbiótica no solo produce toxinas urémicas y una variedad de metabolitos nocivos, sino también puede potencialmente disminuir la producción de metabolitos beneficiosos como los AGCC.

La pérdida de la función renal produce un mayor ingreso de urea dentro del tracto gastrointestinal lo cual, junto con el empeoramiento de la asimilación proteica de la dieta, produce gran influjo de proteínas al intestino distal y favorece el desarrollo de bacterias proteolíticas. A través de la ureasa expresada por algunas bacterias intestinales (especialmente Clostridium spp, Enterococcus, Shigella, Escherichia colli, se generan altos niveles de amonio y otros tóxicos que afectan el crecimiento de las bacterias comensales y alteran la permeabilidad de la barrera intestinal, permitiendo la translocación bacteriana y el ingreso de endotoxinas (LPS), desencadenando un estado inflamatorio de bajo grado que colabora con la progresión de la ERC, la enfermedad cardiovascular, la resistencia insulínica, la pérdida de la energía proteica y la alteración del sistema inmune, etc. ${ }^{22-25}$.

En los pacientes en hemodiálisis, el estrés circulatorio sistémico y la isquemia regional recurrente también pueden dañar la barrera intestinal ${ }^{22-25}$.

En la Figura 5 se muestra un esquema de la relación "disbiosis-enfermedad renal". 


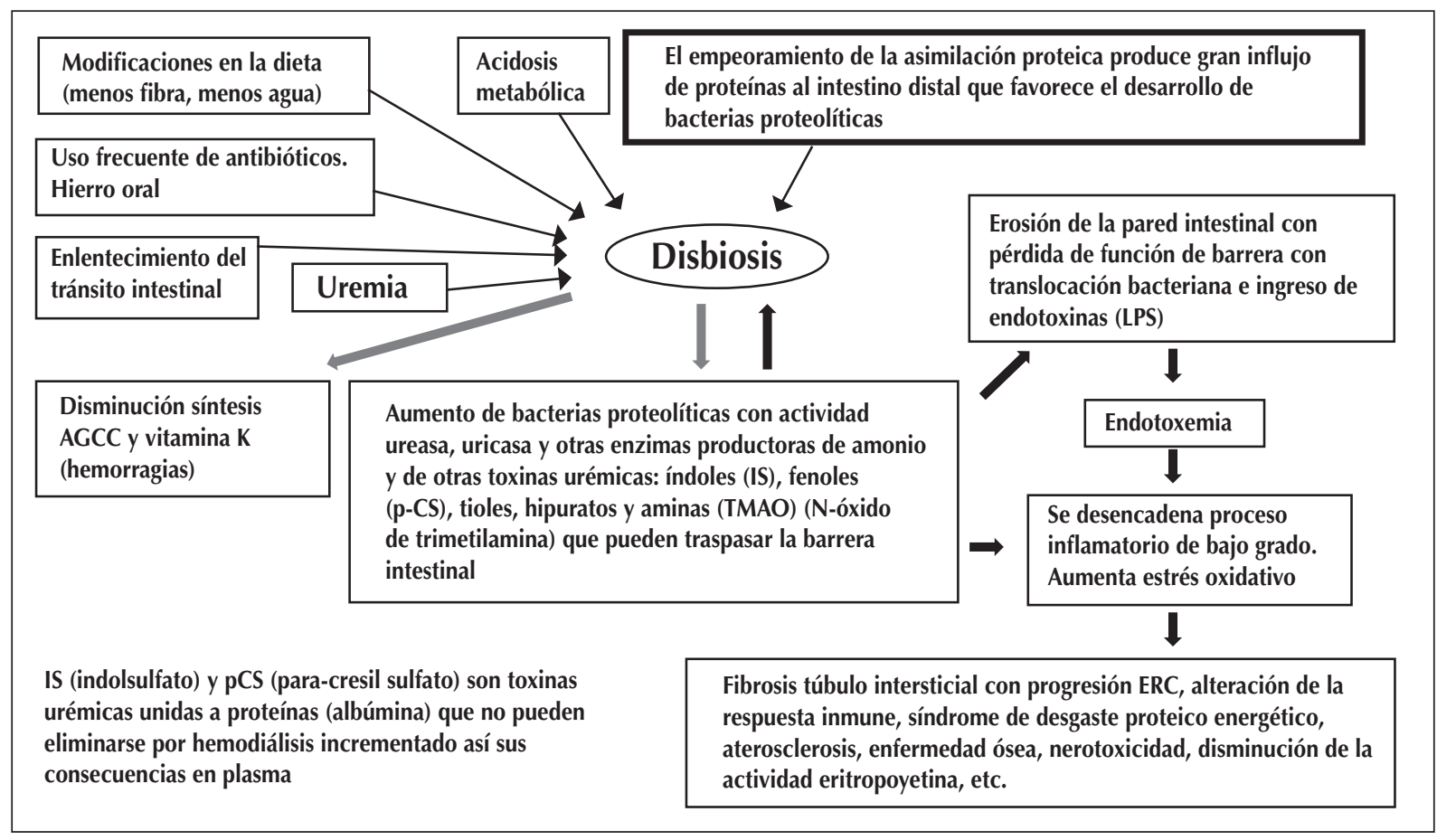

AGCC: ácidos grasos de cadena corta; ERC: enfermedad renal crónica.

Figura 5: Influencia de la disbiosis en el deterioro de la función renal ${ }^{22-25}$.

\section{BIBLIOGRAFÍA}

1. Icaza-Chávez ME. Microbiota intestinal en la salud y la enfermedad. Revista de Gastroenterología de México 2013; 78(4):240-248.

2. Rinninella $E$, Raoul $P$, Cintoni $M$, et al. What is the healthy gut microbiota composition? A changing ecosystem across age, environment, diet, and diseases. Microorganisms 2019; 7(1):14 1-22.

3. Thursby $E$, Juge N. Introduction to the human gut microbiota. Biochem J 2017; 474(11):1823-1836.

4. lizuka K. Recent progress on the role of ChREBP in glucose and lipid metabolism. Endocrine Journal 2013; 60 (5): 543-555.

5. Cani PD, Van Hul M, Lefort C, et al. Microbial regulation of organismal energy Homeostasis. Nature Metabolism 2019; 34 (1):34-46.

6. Chakraborti CK. New found link between microbiota and obesity. World J Gastrointest Pathophysiol 2015; 6 (4):110-119.

7. Morrison DJ, Preston T. Formation of short chain fatty acids by the gut microbiota and their impact on human metabolism. Gut Microbes 2016; 7(3):189-200.

8. Alex S, Lange K, Amolo T, et al. Short-chain fatty acids stimulate angiopoietin-Like 4 synthesis in human colon adenocarcinoma cells by activating peroxisome proliferator-activated receptor $\gamma$. Mol Cell Biol 2013; 33(7):1303-1316.

9. Korecka A, De Wouters T, Cultrone A, et al. ANGPTL-4 expression induced by butyrate and rosiglitazone in human intestinal epithelial cells utilizes independent pathways. Am J Physiol Gastrointest Liver Physiol 2013; 304:G1025-G1037.

10. Musso G, Gambino R, Cassader M. Obesity, diabetes, and gut microbiota the hygiene hypothesis expanded. Diabetes Care 2010; 33:2277-2284.

11. Wu X, WuY, He L, et al. Effects of the intestinal microbial metabolite butyrate on the development of colorectal cancer. Journal of Cancer 2018; 9 (14):2510-2517.

12. Ley RE, Backhed F, Turnbaugh $P$, et al. Obesity alters gut microbial ecology. Proc Natl Acad Sci U S A 2005; 102:11070-11075.

13. Ley RE, Turnbaugh PJ, Klein S, Gordon JI. Microbial ecology: human gut microbes associated with obesity. Nature 2006; 444:1022-1023.
14. Hartstra A, Bouter $K$, Bäckhed $F$, et al. Insights into the role of the microbiome in obesity and type 2 diabetes. Diabetes Care 2015; 38:159-165.

15. Poupeau A, Postic C. Cross-regulation of hepatic glucose metabolism via ChREBP and nuclear receptors. Biochimica et Biophysica Acta 2011; 1812:995-1006.

16. Al-Assal K, Martínez A, Torrinhas $R$, et al. Gut microbiota and obesity. Clinical Nutrition Experimental 2018; 20:60-64.

17. Kootte R, Vrieze A, Holleman F. The therapeutic potential of manipulating gut microbiota in obesity and type 2 diabetes mellitus. Diabetes, Obesity and Metabolism 2012; 14:112-120.

18. Ding S, Chi MM, Scull BP, et al. High-fat diet: bacteria interactions promote intestinal inflammation, which precedes and correlates with obesity and insulin resistance in mouse. PloS One 2010; 5: e12191.

19. Boutagy N, McMillan R, Frisard M, et al. Metabolic endotoxemia with obesity: $\sum$ is it real and is it relevant? Biochimie 2016; 124:11-20

20. Cani P, Amar J, Iglesias M, et al. Metabolic endotoxemia initiates obesity and insulin resistance. Diabetes 2007; 56:1761-1772.

21. Kallio $K A E$, Hätönen $K A$, Lehto $M$, et al. Endotoxemia, nutrition, and cardiometabolic disorders. Acta Diabetol 2015; 52 (2):395-404.

22. Castillo-Rodríguez E, Fernández R, Esteras R, et al. Impact of altered intestinal microbiota on chronic kidney disease progression. Toxins (Basel) 2018; 10(7):300:1-21.

23. Ramezani A, Raj D. The gut microbiome, kidney disease, and targeted interventions. J Am Soc Nephrol 2014; 25:657-670.

24. Osuna-Padilla IA, Leal-Escobar G. Alteraciones en el eje intestino-riñón durante la enfermedad renal crónica: causas, consecuencias y propuestas de tratamiento. Rev Esp Nutr Hum Diet 2017; 21(2):174-83

25. Ramezani A, Massy Z, Meijers B, et al. Role of the gut microbiome in uremia: a potential therapeutic target. Am J Kidney Dis $2016 ; 67(3): 483-498$ 


\section{CB y CM: definición, indicaciones y contraindicaciones. Selección de pacientes. Tipos de procedimientos. Manejo pre quirúrgico en pacientes con DM. Riesgos perioperatorios}

\section{Definición}

El término cirugía bariátrica $(\mathrm{CB})$ deriva de la raíz griega donde baros significa relativo al peso e iatrikos, medicina. Define al conjunto de intervenciones quirúrgicas diseñadas para producir pérdidas importantes de peso y su mantenimiento a largo plazo ${ }^{1,2}$.

Se denomina cirugía metabólica (CM) a la intervención que se realiza sobre el tubo digestivo con el objetivo de conseguir la mejoría o remisión de la DM2 y la reducción del riesgo cardiometabólico por mecanismos independientes a la reducción de peso, considerándose hoy una opción terapéutica para el tratamiento de la DM2 $2^{1,3}$.

\section{Indicaciones}

- Adultos con índice de masa corporal (IMC) $\geq 40 \mathrm{~kg} / \mathrm{m}^{2}$.

- Adultos con IMC entre 35 y $39,9 \mathrm{~kg} / \mathrm{m}^{2}$ con al menos una comorbilidad asociadas como: DM2, apnea obstructiva del sueño (OSA, por sus siglas en inglés), HTA, dislipidemia (DLP), síndrome de hipoventilación-obesidad (OHA, por sus siglas en inglés), síndrome de Pikwick, enfermedad hepática grasa no alcohólica (NAFLD, por sus siglas en inglés), esteatohepatitis no alcohólica (NASH, por sus siglas en inglés), pseudotumor cerebral, reflujo gastroesofágico, asma, síndrome de ectasia venosa, incontinencia urinaria severa, artritis incapacitante, mala calidad de vida, contraindicaciones de otras cirugías como consecuencia de la obesidad.

- Adultos con IMC entre $30-34,9 \mathrm{~kg} / \mathrm{m}^{2}$ con DM2 con inadecuado control metabólico ${ }^{4}$ y SM (aunque aún no hay evidencias a largo plazo para realizar esta cirugía rutinariamente) $)^{5}$.

- Obesidad de al menos cinco años de evolución, con fracaso a los tratamientos conservadores debidamente supervisados.

- Compromiso del paciente a adherir a los controles posquirúrgicos, seguimiento, cuidados alimentarios indicados y toma de los suplementos vitamínicos.

Los criterios de inclusión para la selección de pacientes para $\mathrm{CM}$, según el Consenso Argentino de Cirugía Metabólica, son"

- Dos o más criterios mayores.
- Un criterio mayor o dos criterios menores.

- Criterios de inclusión básicos: DM2 $\geq 2$ años de evolución; edad $\leq 65$ años (excepto condición especial que lo haga recomendable); $\mathrm{HbA} 1 \mathrm{c}>8 \%$ durante al menos un año, con fracaso al tratamiento médico adecuado y combinado con triple terapia farmacológica; indicación quirúrgica realizada por médico especialista en enfermedades endocrino-metabólicas en forma conjunta con equipo quirúrgico debidamente constituido y entrenado en CM; IMC 30-34,9 kg/m²; circunferencia de cintura en hombres $>102 \mathrm{~cm}$ y en mujeres $>88$ $\mathrm{cm}$; péptido $\mathrm{C}$ en ayunas $>1 \mathrm{ng} / \mathrm{dl}$; compromiso y adherencia a la preparación y posibilidad de seguimiento con el equipo interdisciplinario.

- Criterios mayores: HTA, dislipemia, antecedentes personales de enfermedad macro y/o microvascular, síndrome de apnea/hipopnea obstructiva de sueño (SAHOS) moderada-severa.

- Criterios menores: hiperinsulinemia de ayuno definida por insulinemia en ayunas $\geq 20 \mathrm{mcU} /$ $\mathrm{ml}$ (en pacientes sin tratamiento con insulina exógena), espesor de la capa íntima media carotidea $\geq 1 \mathrm{~mm}$, historia familiar de eventos cardiovasculares, infarto agudo de miocardio (IAM), accidente cerebrovascular (ACV) en familiares de primer grado (padre $<55$ años y/o madre $<65$ años), NAFLD diagnosticada por enzimas hepáticas elevadas y/o métodos de diagnóstico por imágenes.

La Cumbre de Cirugía de la Diabetes ${ }^{6}$ propuso un algoritmo de tratamiento para DM2 donde incluye CM en pacientes con: IMC $\geq 40 \mathrm{~kg} / \mathrm{m}^{2}$ (IMC $>37,5 \mathrm{~kg} / \mathrm{m}^{2}$ en los asiáticos), independiente del control glucémico o complejidad de tratamiento, IMC 35-39,9 kg/m² $\left(32,5-37,4 \mathrm{~kg} / \mathrm{m}^{2}\right.$ en asiáticos) con hiperglucemia inadecuadamente controlada a pesar de los cambios del estilo de vida y el tratamiento médico óptimo. Considerar en pacientes con IMC 30-34,9 kg/m² $\left(27,5-32,4 \mathrm{~kg} / \mathrm{m}^{2}\right.$ en los asiáticos) e hiperglucemia inadecuadamente controlada a pesar del tratamiento médico óptimo (oral o inyectable).

\section{Contraindicaciones}

- Consumo o abuso de drogas y/o alcohol.

- Enfermedades psiquiátricas severas sin tratamiento o no controladas.

- Bulimia asociada a severa obesidad.

- Enfermedades con corta expectativa de vida.

- Enfermedad cardiovascular severa con contraindicación absoluta de anestesia. 
- Coagulopatías severas.

- Incapacidad del paciente de cumplir con los requerimientos nutricionales y de cambios en el estilo de vida, así como falta de comprensión de los beneficios y los riesgos.

- Controversial: mayores de 65 años de edad y menores de 18 años.

- Embarazo.

- El abuso de tabaco o dependencia de la nicotina se considera una contraindicación relativa (esta condición debe tratarse antes de la cirugía).

- Es un procedimiento que no debe realizarse para el control de la glucemia, lípidos o como reducción del riesgo cardiovascular independientemente del IMC.

- Autoinmunidad positiva definida por anticuerpos anti GAD, solo para CM.

A la fecha hay muy pocos estudios sobre el impacto de la CB en pacientes con DM1. En DM1 con obesidad mórbida, se observó una mejoría del control glucémico y una reducción en las dosis diarias de insulina. Sin embargo, se requieren más estudios para conocer con mayor precisión los efectos de la CB en estos pacientes ${ }^{3,7,8}$.

\section{Tipos de procedimientos quirúrgicos}

Los procedimientos que se utilizan en la actualidad inicialmente se clasificaron según sus mecanismos de acción en restrictivos y/o malabsortivos. Los restrictivos reducen el tamaño del estómago $y$, consecuentemente, la ingesta, manteniendo las funciones del aparato digestivo intactas; los malabsortivos alteran el trayecto del alimento.

El bypass gástrico en $Y$ de Roux (BGYR) es un procedimiento mixto: se crea una pequeña bolsa estomacal al dividir el estómago y unirlo al intestino delgado (se anastomosa a un asa yeyunal en Roux), la cual solo puede contener $30 \mathrm{ml}$, y generar sensación de plenitud con cantidades muy pequeñas de alimentos, los cuales saltean la mayor parte del estómago e intestino delgado superior (duodeno). Este procedimiento parece causar una disminución del apetito y mejorar el metabolismo al modificar la liberación de varias hormonas como grelina, PYY, GLP-1 y colecistoquinina. El BGYR por vía laparoscópica es la técnica más aceptada, de mayor seguridad y eficacia, con mayor tasa de remisión de DM2 a largo plazo que otros procedimientos restrictivos, siendo considerado el procedimiento gold standard ${ }^{2,4}$.

La derivación biliopancreática es un procedimiento malabsortivo: gastrectomía parcial y gas- troileostomía con un segmento largo de la extremidad Roux y un canal común corto (la parte del intestino delgado que recibe los alimentos y secreciones biliopancreáticas) produciendo malabsorción de grasa y almidones; es técnicamente difícil, con un alto índice de complicaciones, por lo cual ha quedado prácticamente en desuso.

En la gastrectomía en manga (sleeve gastrectomy, SG, por sus siglas en inglés) se elimina la mayor parte de la curvatura mayor del estómago y se crea un estómago tubular, con pequeña capacidad y resistente al estiramiento por la ausencia del fundus; la disminución de las células productoras de grelina aumenta los niveles de GLP-1 y PYY. Es un procedimiento restrictivo.

La banda gástrica ajustable laparoscópica es un procedimiento puramente restrictivo que compartimenta la parte superior del estómago mediante la colocación de una banda protésica estrecha y ajustable alrededor de la entrada del estómago (bolsa proximal de alrededor de $30 \mathrm{ml}$ ). Ese anillo de silicona queda conectado a un puerto de infusión colocado en el tejido subcutáneo, al cual se puede acceder con relativa facilidad para la inyección de solución salina, con reducción en el diámetro de la banda, resultando en un mayor grado de restricción. Es un procedimiento relativamente seguro y poco invasivo en comparación con otros, sin embargo la pérdida de peso es más lenta².

El balón intragástrico es un globo blando lleno de solución salina, colocado endoscópicamente, que promueve sensación de saciedad y restricción, como alternativa temporal.

Los dos procedimientos más frecuentemente realizados son la SG y el BGYR².

\section{Manejo prequirúrgico}

La evaluación incluirá una historia clínica completa, historia psicosocial, examen físico, evaluación nutricional y estudios de laboratorio que incluyan micronutrientes. La prevalencia de patología cardíaca y pulmonar en los individuos con obesidad mórbida es elevada, por lo cual deben tener una evaluación cardiovascular ${ }^{9}$. En los pacientes con $\mathrm{DM}^{9}$, hay que considerar el tipo de diabetes y años de enfermedad, control glucémico, episodios de complicaciones agudas (cetoacidosis, coma hiperosmolar e hipoglucemias), complicaciones microvasculares (retinopatía, nefropatía, neuropatía sensitiva, motora, autonómica, incluyendo disfunción sexual y gastroparesia) y macrovascula- 
res, (enfermedad cardiovascular, cerebrovascular y vascular periférica), así como otros factores de riesgo asociados. Se debe evaluar el tratamiento farmacológico, la adherencia del paciente y el automonitoreo glucémico.

En el laboratorio debe incluirse glucemia, $\mathrm{HbA} 1 \mathrm{c}$, péptido C, perfil lipídico, hepatograma, albúmina/ creatinina en muestra aislada de orina, creatinina sérica, cálculo del filtrado glomerular por MDRD (Modification of diet in renal disease) y anticuerpos anti GAD cuando estén disponibles. Se debe optimizar el control glucémico preoperatorio $0^{6,10,11}$. Los valores sugeridos en control preoperatorio son: $\mathrm{HbA} 1 \mathrm{c}$ $\leq 7 \%$, glucemia en ayunas $\leq 110 \mathrm{mg} / \mathrm{dl}$ y posprandial $\leq 140 \mathrm{mg} / \mathrm{dl}$. Se recomienda considerar valores entre 7 y $8 \%$ de $\mathrm{HbA} 1 \mathrm{c}$ en pacientes con complicaciones macro o microvasculares avanzadas, condiciones de comorbilidad o DM de larga evolución con dificultades para alcanzar el objetivo. En pacientes con $\mathrm{HbA} 1 \mathrm{c}>8 \%$ o DM no controlada, el juicio clínico determinará la oportunidad de la cirugía.

Los antidiabéticos deben tomarse normalmente el día previo a la cirugía y suspenderse ese mismo día, excepto la metformina que deberá suspenderse $48 \mathrm{~h}$ antes del procedimiento si se utilizan sustancias de contraste o si la depuración de creatinina es $<50 \mathrm{ml} / \mathrm{min}$.

Se sugiere a todos los pacientes la prevención de trombosis venosa profunda a través de dispositivos de compresión secuencial y administración de heparina no fraccionada o de bajo peso molecular dentro de las $24 \mathrm{~h}$ posquirúrgicas.

La evaluación de los estudios complementarios deberá ser orientada por sistemas ${ }^{6}$ :

- Cardiovascular: electrocardiograma de reposo, ecocardiograma si se conoce o se sospecha la existencia de hipertensión pulmonar o enfermedad cardíaca.

- Respiratorio: radiografía de tórax, espirometría y screening estandarizado para SAOS (polisomnografía confirmatoria si el screening es positivo y gases en sangre arterial).

- Gastrointestinal: videoendoscopia digestiva alta (VEDA) o seriada esofagogastroduodenal (especialmente en candidatos a BGYR), detección de infección por Helicobacter Pylori y ecografía abdominal hepatobiliopancreática.

- Ginecológico: subunidad B a mujeres en edad reproductiva y recomendar evitar el embarazo en el preoperatorio y durante los 12-18 meses posteriores a la CB. La terapia con estrógenos debe ser discontinuada antes de la cirugía para reducir el riesgo de fenómenos tromboembólicos durante el posoperatorio. Realizar screening para la detección de cáncer según edad y riesgo.

Suspender el consumo de tabaco al menos seis semanas antes de la CB y evitarlo en el posquirúrgico por riesgo de cicatrización deficiente de heridas y úlcera anastigmática6.

\section{Riesgo perioperatorio}

La mortalidad intrahospitalaria posquirúrgica disminuyó de 0,8\% en 1998 a 0,10\% en 2008 en Estados Unidos. Se observó una mortalidad más baja en hospitales de alto volumen de procedimientos en comparación con los de bajo volumen $(0,3 \% \text { vs } 1,2 \% \text { respectivamente })^{12}$.

Las complicaciones quirúrgicas son ${ }^{12}$ :

- Náuseas, vómitos y dolor abdominal, diarrea, deshidratación, estreñimiento.

- Síndrome de Dumping, hipoglucemias.

- Dehiscencia de anastomosis, filtraciones, fístulas, hernias internas y/o isquemia intestinal, úlceras, sangrado, estenosis de la neoboca, reflujo gastroesofágico, obstrucción, erosiones por dispositivos (la banda gástrica ajustable puede cursar con desplazamiento o incluso erosión hacia el lumen gástrico).

- Infección del sitio quirúrgico, hernias/hematomas de la pared abdominal.

- Complicaciones pulmonares, dificultad para la intubación, tromboembolismo de pulmón, reintubación traqueal.

- Litiasis, infección urinaria, rabdomiólisis, insuficiencia renal.

- Deficiencias nutricionales

- Trombosis venosa profunda.

\section{BIBLIOGRAFÍA}

1. Lee $W$ J, Almulaifi A. Recent advances in bariatric/metabolic surgery: appraisal of clinical evidence. Biomed Res 2015 Apr; 29(2): 98-104. DOI: 10.7555/JBR.28.20140120.

2. Landecho MV, Valentí V, Moncada R, et al. Eligibility and success criteria for bariatric/metabolic surgery. Adv Exp Med Biol 2017; 960: 529-543. DOI: 10.1007/978-3-319-48382-5-23.

3. Akcay MN, Karadeniz E, Ahiskalioglu A. Bariatric/metabolic surgery in type 1 and type 2 diabetes mellitus. Eurasian J Med 2019; 51(1):85-89. DOI: 10.5152/eurasianjmed.2018.18298

4. Consenso Argentino de Cirugía Metabólica. Revista de la Sociedad Argentina de Diabetes 2015; Vol. 49: 95-110.

5. Mechanick JI, Youdim A. Jones DB, et al. Clinical practice guidelines for the perioperative nutritional, metabolic, and nonsurgical support of the bariatric surgery patient 2013 Update: Cosponsored by American Association of Clinical Endocrinologists, The Obesity Society, and American Society for Metabolic \& Bariatric. Surgery for Obesity and Related Diseases 2013; 9:159-191. 
6. Fried M, Yumuk V, Oppert J M, et al. International Federation for the Surgery of Obesity and Metabolic Disorders-European Chapter (IFSO-EC) and European Association for the Study of Obesity (EASO) Interdisciplinary European Guidelines on metabolic and bariatric surgery. Obes Surg 2014; 24(1):42-55. DOI: 10.1007/ s11695-013-1079-8.

7. Almageeb $\mathrm{H}$, Abdelgadir $\mathrm{E}$, Bashier A, et al. Efficacy of bariatric surgery in improving metabolic outcomes in patients with diabetes. A 24-month follow-up study from a single center in the UAE. Targets andTherapy 2018; 3(11):459-467.

8. Brethauer SA, Aminian A, Rosenthal R J, et al. Bariatric surgery improves the metabolic profile of morbidly obese patients with type 1 diabetes. Diabetes Care 2014; 37(3):e51-2. DOI: 10.2337/ dc13-1736.
9. Pampillón $\mathrm{N}$, et al. Actualización del Consenso Argentino de Nutrición en Cirugía Bariátrica. Actualización en Nutrición 2016; Vol. 17, $\mathrm{N}^{\circ} 1$ marzo:19-32.

10. Rubino F, Nathan DM, Ecke $\mathrm{RH}$, et al. Metabolic surgery in the treatment algorithm for type 2 diabetes: $A$ joint statement by international diabetes organizations. Diabetes Care 2016; 39(6):861-877.

11. Mechanick JI, Youdim A, Jones DB. Clinical Practice Guidelines for the perioperative nutritional, metabolic, and nonsurgical support of the bariatric surgery patient-2013 update: cosponsored by American Association of Clinical Endocrinologists. The Obesity Society and American Society for Metabolic and Bariatric Surgery. Endocrine Practice 2013; 19:1-36.

12. Nguyen N, Paya M, Stevens M, Mavandadi S, Zainabadi K, Wilson $\mathrm{S}$. The relationship between hospital volume and outcome in bariatric surgery at Academic Medical Centers. Ann of Surg 2004; 240(4):586-93.

\section{Efectos de la CB en preservar la función renal y en la morbimortalidad del paciente con DM y enfermedad renal}

\section{¿Cómo evaluar tasa de filtrado glomerular? ¿Medición o estimación?}

La determinación de la tasa de filtrado glomerular (TFG) es el mejor índice para evaluar la función renal (FR), así como el grado de alteración y la progresión de la ERC. Se filtran 180 litros de plasma por día aproximadamente $(125 \mathrm{ml} / \mathrm{min})$, pero el valor real depende de la edad, sexo y tamaño corporal (130 y $120 \mathrm{ml} / \mathrm{min} / 1,73 \mathrm{~m}^{2}$ en hombres y mujeres, respectivamente), con variaciones interindividuales.

Existen múltiples formas complejas de valorar la TFG con exactitud (aclaramiento de inulina, iotalamato, iohexol) pero en la práctica clínica diaria se realiza mediante fórmulas basadas en la creatinina sérica (Crs) a través del clearance de creatinina.

El clearance de creatinina medido ( $\mathrm{ClCr}-\mathrm{m})$ puede modificarse por el estado nutricional, la masa muscular, la ingesta de carne o dietas vegetarianas, pudiéndose sobrevalorar la TFG, dado que la Crs es filtrada y secretada por el túbulo renal (10$20 \%$ mayor) e infravalorar por errores en la recolección de la muestra de diuresis de 24 h. Debería considerarse realizar la indexación o el ajuste del CICr-m a la superficie corporal (SC).

En consecuencia, se generaron diferentes ecuaciones diseñadas en base al uso del valor de la Crs en relación a edad, sexo, peso, talla y raza/ etnia, obviando la necesidad de recoger orina de 24 h. Se define así el $\mathrm{ClCr}$ estimado o calculado $(\mathrm{ClCr}$ e), siendo las fórmulas más utilizadas Modification of diet in renal disease (MDRD) y Chronic Kidney Disease Epidemiology Collaboration (CKD-EPI)'.
La ecuación CKD-EPI se desarrolló para proveer una estimación más exacta en individuos con TFG normal o levemente reducida, incluyendo población con y sin ERC, con amplio rango de TFG².

Dadas las dificultades con los cambios en la producción y secreción de $\mathrm{Cr}$, se diseñaron ecuaciones que incluyen cistatina $\mathrm{C}$ (cysC) con modificaciones según sexo masculino, talla y peso elevados, masa magra elevada, masa grasa, marcadores de inflamación, edad y trastornos tiroideos. Se ha postulado que los niveles séricos de cys $C$ correlacionan con mayor exactitud con la TFG comparado con $\mathrm{Crs}^{3}$. La combinación de ambas determinaciones en una sola ecuación parecería definir una mejor estimación de TFG que si se utilizan en forma aislada ${ }^{4}$.

\section{Marcadores de filtrado glomerular para determinación de TFG en sujetos con CB}

La pérdida de masa muscular con descenso rápido e importante de peso genera una sobrestimación de TFG luego de la realización de $\mathrm{CB}^{5}$. En la población general la evidencia se basa en estimaciones de TFG más que en mediciones de TFG. El valor en la población obesa es limitado: primero, las ecuaciones se formularon a partir de población no obesa, sin poder validarlas; segundo, el descenso de peso posquirúrgico implica disminución de la masa muscular y masa grasa; tercero, existe un fenómeno de hiperfiltrado glomerular que favorece el descenso de niveles de Crs prequirúrgicos, lo cual revierte con el descenso de peso. Es de destacar que la cysC permite inferir la TFGe sin influencia de la masa muscular, definiéndose como un marcador probablemente más fiable de FR en población obesa ${ }^{6}$.

El uso de CKD-EPI Cr-cys $C$ es la que mejor estima TFGm antes y después de la cirugía, por lo cual se sugiere el uso de múltiples marcadores de 
filtrado en futuras investigaciones de cambios en la FR en el contexto de CB.

\section{Efectos de la CB en FR medida en pacientes con TFG conservada}

En un metaanálisis, Navaneethan et al. ${ }^{9}$ evidenciaron, en una población con TFG normal o elevada que se sometió a $\mathrm{CB}$, una reducción de laTFG m no indexada en promedio de $25 \mathrm{~mL} / \mathrm{min}$. No obstante, para definir si esa normalización del hiperfiltrado podría extrapolarse a beneficios renales a largo plazo, deberían desarrollarse nuevos estudios.

\section{Efectos de la CB en FR medida en pacientes con ERC}

Un número limitado de estudios evaluó el efecto de la CB en pacientes con ERC. En un estudio realizado por Navaneethan et al. se evaluaron pacientes con creatinina plasmática $\geq 1,3 \mathrm{mg} / \mathrm{dl}$ y se realizó medición TFG $m$ con iothalamato previo a la cirugía 3,6 y 12 meses posteriores a la misma. A diferencia de los estudios con TFG conservada, esta determinación medida no indexada se mantuvo sin cambios a los 12 meses $(82,0-80,5 \mathrm{ml} / \mathrm{min}, \mathrm{P}=0,3)$, mientras que cuando se realizó TFG $m$ indexada a $\mathrm{SC}$, la TFG $\mathrm{m}$ se incrementó de 50 a $64 \mathrm{ml} / \mathrm{min} / 1,73 \mathrm{~m}^{2}$ a los 12 meses $(p=0,02)^{10}$. Se observó que existe relación entre estos incrementos y los descensos en niveles de leptina, lo que permite inferir que la inflamación y disregulación de adipocitoquinas pueden considerarse factores que favorecerían el desarrollo de ER en este grupo poblacional11.

Tanto la albuminuria como la proteinuria han descendido pos-CB. De todas formas, no puede definirse si el beneficio es por efecto directo del descenso de peso o por mejora de niveles de tensión arterial y/o resistencia a la insulina ${ }^{12}$.

\section{Efectos de la $\mathrm{CB}$ en resultados renales}

Chang et al. ${ }^{13}$ compararon una cohorte que realizó CB vs tratamiento no quirúrgico, en un seguimiento a 9 años, evaluando eventos renales. En el grupo CB se observó una reducción del 58\% del riesgo descenso de TFG y disminución del $57 \%$ de duplicación de creatinina o ESRD (eGFR $<15 \mathrm{ml} / \mathrm{min} / 1,73 \mathrm{~m}^{2} \mathrm{o}$ ingreso a diálisis) (Figura 1). El efecto protector asociado con la CB persistió en aquellos con TFG <90 mL/min/1,73 m², HTA y DM. Con respecto a la trayectoria de la TFGe, el grupo en que se realizó cirugía experimentó inicialmente un incremento de 4,6 mL/min/1,73 $\mathrm{m}^{2}$ al primer año y reducción de 0,7 mL/min/1,73 $\mathrm{m}^{2}$ al final del quinto año, comparado con basal. El grupo que realizó tratamiento no quirúrgico experimentó disminución media de $1,5 \mathrm{~mL} / \mathrm{min} / 1,73 \mathrm{~m}^{2}$ al año y disminución media de 6,3 mL/min/1,73 $\mathrm{m}^{2}$ al finalizar el quinto año, comparado con basal.

Se ha postulado que el tipo de procedimiento quirúrgico podría presentar beneficios renales diferentes. Por ejemplo, en una población de 714 pacientes con ERC E3-4 se reportó una mejora en TFGe luego de la cirugía de bypass gástrico en Y-de- Roux vs manga gástrica con un seguimiento a tres años ${ }^{14}$.

Se ha propuesto que en sujetos con ERC E4-5 y obesidad se realice CB para reducir complicaciones. Así, se ha intentado definir el momento ideal para efectuarla y se evaluó la eficacia del procedimiento de acuerdo a distintos estadios de ERC. Se desarrolló un estudio observacional retrospectivo comparativo, en 101 sujetos con ERC en distintos estadios con diagnóstico de obesidad, y se evaluó la pérdida de peso pos-CB, a los 6 y 12 meses, y se demostró que en estadios avanzados de ERC se evidencia una respuesta menor de pérdida de peso comparado con etapas menos avanzadas ${ }^{15}$ (Figura 2).

Como conclusión, se considera que la eficacia del tratamiento quirúrgico es menor en población con ERC avanzada, lo cual permite considerar que el mismo debería desarrollarse en etapas más precoces de la misma.

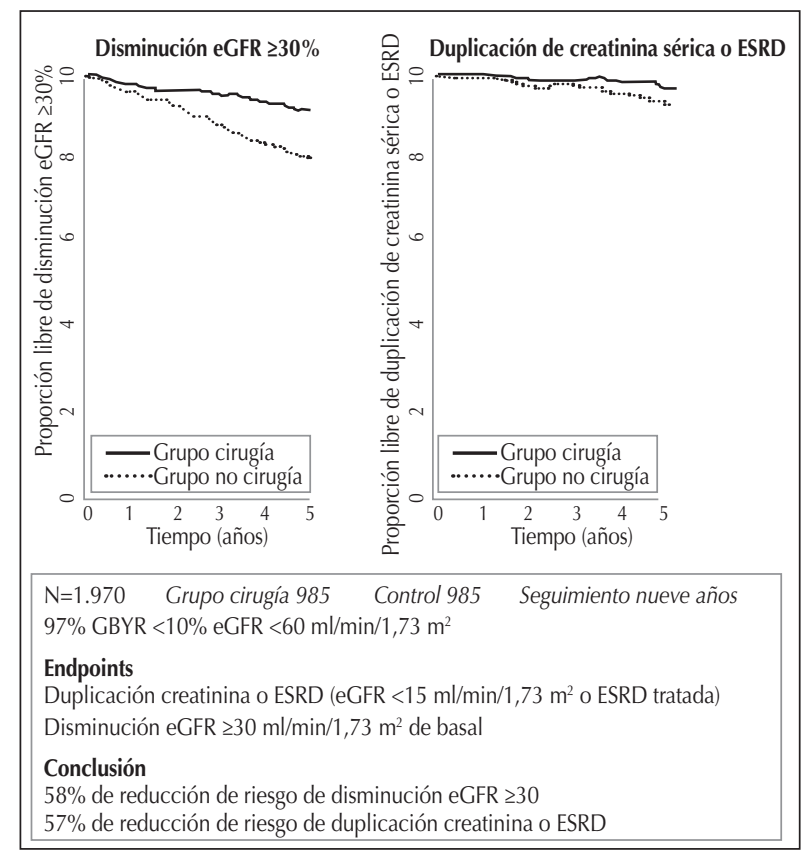

Adaptado de: Chang et al..$^{13}$.

eGFR: tasa de filtrado glomerular estimada; ESRD: enfermedad renal crónica estadio final; BGYR: bypass gástrico en Y de Roux.

Figura 1: Resultados renales por grupo de tratamiento. 


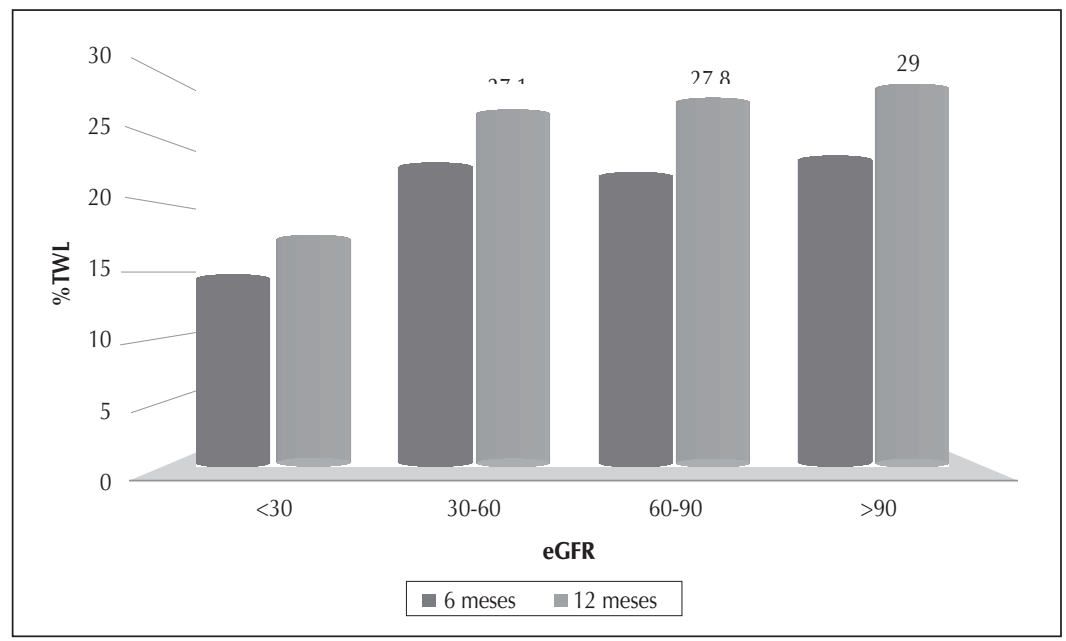

Adaptado de: Hansel et al. ${ }^{15}$.

\%TWL: porcentaje de pérdida de peso total; eGFR: tasa de filtrado glomerular estimada.

Figura 2: Porcentaje de reducción de peso total poscirugía bariátrica según estadios ERC.

\section{BIBLIOGRAFÍA}

1. Kidney Disease: Improving Global Outcomes (KDIGO) CKD Work Group. KDIGO 2012 Clinical Practice Guideline for the Evaluation and Management of Chronic Kidney Disease. Kidney Int 2013; 3 (Suppl):1-150.

2. Levey AS, Stevens LA, Schmid CH, Zhang $Y L$, Castro AF, Feldman HI, Kusek JW, Eggers P, Van Lente F, GreeneT, Coresh J, CKD-EPI (Chronic Kidney Disease Epidemiology Collaboration). A new equation to estimate glomerular filtration rate. Ann Intern Med 2009; 150(9):604-12.

3. Stevens LA, Coresh J, Schmid CH, et al. Estimating GFR using serum cystatin $\mathrm{C}$ alone and in combination with serum creatinine: a pooled analysis of 3,418 individuals with CKD. Am J Kidney Dis 2008; 51(3):395-406.

4. Inker LA, Schmid $\mathrm{CH}$, Tighiouart $\mathrm{H}$, Eckfeldt JH, Feldman HI, Greene T, Kusek JW, Manzi J, Van Lente F, Zhang YL, Coresh J, Levey AS, CKD-EPI Investigators. Estimating glomerular filtration rate from serum creatinine and cystatin C. N Engl J Med 2012; 367(1):20-9

5. Chang AR, Greene T, Wang $X$, et al. The effects of weight change on glomerular filtration rate. Nephrol Dial Transplant 2015; 30 (11):1870-7.

6. Baxmann AC, Ahmed MS, Marques NC, et al. Influence of muscle mass and physical activity on serum and urinary creatinine and serum cystatin c. Clin J Am Soc Nephrol 2008; 3 (2): 348-354.

7. Friedman AN, Moe S, Fadel WF, et al. Predicting the glomerular filtration rate in bariatric surgery patients. Am J Nephrol 2014; 39:8-15.
8. Brøchner-Mortensen J, Rickers H, Balslev I. Renal function and body composition before and after intestinal bypass operation in obese patients. Scand J Clin Lab Invest 1980; 40(8):695-702.

9. Navaneethan SD, Yehnert H, Moustarah F, et al. Weight loss interventions in chronic kidney disease: a systematic reviewand metaanalysis. Clin J Am Soc Nephrol 2009; 4 (10):1565-74.

10. Navaneethan SD, Malin SK, Arrigain S, et al. Bariatric surgery, kidney function, insulin resistance, and adipokines in patients with decreased GFR: a cohort study. Am J Kidney Dis 2015; 65(2):342-347.

11. MacLaughlin $\mathrm{HL}$, Hall WL, Patel AG, et al. Weight loss, adipokines, and quality of life after sleeve gastrectomy in obese patients with stages 3-4 CKD: a randomized controlled pilot study. Am J Kidney Dis 2014; 64(4):660-3.

12. Li K, Zou J, Ye Z, et al. Effects of bariatric surgery on renal function in obese patients: a systematic review and meta analysis. PLoS One 2016;11(10):e0163907.

13. Chang AR, Chen Y, Still C, et al. Bariatric surgery is associated with improvement in kidney outcomes. Kidney Int 2016; 90:164-171.

14. Imam TH, Fischer $H$, Jing $B$, et al. Estimated GFR before and after bariatric surgery in CKD. Am J Kidney Dis 2017; 69(3):380-388.

15. Hansel B, Arapis K, Kadouch D, et al. Severe chronic kidney disease is associated with a lower efficiency of bariatric surgery. Obes Surg 2019; 29(5):1514-1520. 